\title{
ADDRESSING SERVICE ACCESS BARRIERS FOR HOMELESS YOUTH: A CALL FOR COLLABORATION
}

\author{
Jeffrey L. PERRON \\ University of Ottawa, Canada
}

\begin{abstract}
Homeless youth are among the most vulnerable individuals in North American society. The day-to-day stressors they face while living on the streets pose a great threat to their mental and physical health. A number of barriers that youth face in accessing care have been identified in the literature. This discussion article highlights work that has been done to apply geographic theory to issues of service access among homeless youth. To date, most such work has been theoretical in nature, with collaborations between geographers and homeless youth researchers to make applied recommendations for the location of services. Urban geographers and homeless youth researchers are implored to collaborate in order to make recommendations that will increase the access to service, particularly for rural homeless youth.
\end{abstract}

Key Words: homeless, youth, health services, health care.

\section{Introduction}

Homeless youth are among the most vulnerable individuals in North American society (Kidd 2003). Given their vulnerability, victimization, and generally poor physical and mental health, access to health services is critical to survival on the streets (Kidd 2003). However, homeless youths' ability to access the services they need is limited by a number of factors. Well documented barriers to service access for homeless youth and other homeless populations include issues of mistrust towards professionals and authorities, lack of health insurance, and issues related to gender and ethnicity (Thompson et al. 2006a, Kidd 2003, Aviles and Helfrich 2004, Berdhal et al. 2005). Increasingly, however, barriers that are geographic in nature are receiving research attention. This includes research on the location of services and homeless youths' diminished access to adequate forms of transportation. Researchers studying homeless youth are recognizing the role of urban geographic theory in properly addressing the barriers that homeless youth experience in accessing health services (Baker Collins 2013, Elias 2009, Thompson et al. 2006a). That said, the influence of geographic theory and interventions has been more commonly applied to issues concerning adult homelessness. Few works have been dedicated to the application of geographic theory and interventions to issues unique to youth homelessness.

While many of the "on-the-street" stressors are similar for both urban and rural homeless youth, there are key differences as they relate to access to services. The rate of overall homelessness is approximately 14 homeless individuals for every 10,000 people in rural areas. This is less than half the 29 of 10,000 persons rate found to exist in urban settings. The lower number of homeless individuals in rural settings generally means a much lower concentration of homeless youth in rural areas than in urban areas, as would be expected. Perhaps paradoxically, the lack of a "critical mass" of homeless youth in rural settings means that rural homeless youth assistance services and systems are rare. Where they do exist, they often lack the 
infrastructure to provide comprehensive care to these youth. In addition to the low concentration of homeless youth in rural settings, the lack of available affordable housing, limited public transportation, and low levels of governmental funding contribute to the maintenance of inadequate care for homeless youth in rural settings (National Alliance to End Homelessness 2010).

Further inter-disciplinary collaboration between geographers and mental health professionals will be critical in harnessing urban geographic theory to alleviate these barriers to access, particularly for rural homeless youth. With that in mind, this paper has three aims: 1 ) it seeks to orient the reader to the nature of life on the streets for homeless youth in North America (the scope is limited to the United States and Canada); 2) it seeks to provide a brief overview of research related to the influence of geography and location to homeless youths' ability to access services (of note, discussion of works related to the application of geographic theory and interventions to issues of adult homelessness are outside the scope of the paper); and, 3) it seeks to be a call-to-action for both urban geographers and researchers focused on homeless youth, encouraging discussion and collaboration to address service access barriers.

\section{Materials and Methods}

In order to gather sources for this discussion paper, searches were conducted using the Psyclnfo database. Keywords such as: 'homeless', 'geography', 'youth', 'urban', 'rural' were used along with the criterion that articles were published between 1960 and 2013. Article abstracts were reviewed for relevance. Articles that did not focus on the location or configuration of homeless youth services were rejected. Based on this review, articles most relevant to the current discussion were selected for further analysis.

\section{Life on the Streets}

An understanding of the nature of life as a homeless youth serves to elucidate the grave need for access to appropriate services. This section outlines research conclusions which have outlined the chief characteristics of day-to-day life on the streets for homeless youth. Of note, the majority of this research comes from samples of urban homeless youth given the paucity of research related to rural homeless youth. While the majority of findings apply to some extent to both rural and urban homeless youth, further research is needed to clarify the extent to which life on the streets for rural homeless youth is different from life on the street for urban homeless youth.

Undoubtedly, life on the streets for both sub-populations is characterized by chronic stressors, the most salient of which may be the need to secure shelter and food (Thompson et al. 2006b). Homeless youth who live with this uncertainty with regard to basic needs, spend much of their emotional energy trying to quell the anxiety and fear that stem from these stressors (Thompson et al. 2006b).

Many of the harsh conditions of life on the street translate into serious physical health maladies (Ensign and Bell 2004). Some of the most prevalent aspects of street life leading to physical illness include malnutrition caused by the lack of food or poor quality food and eating habits (Thompson et al. 2006a) and instable or inadequate housing. Furthermore, homeless youth often engage in behaviours that indirectly or directly cause decreases in overall health, such as substance abuse or deviant and criminal activity (Halcon and Lifson 2004). The high rate at which homeless youth engage in risky sexual behaviour has been well documented by researchers (Halcon and Lifson 2004). The result of high rates of such behaviour is the high 
rate of sexually transmitted infections found among the homeless youth population (Halcon and Lifson 2004, Thompson et al. 2006a).

Youth are also targeted for victimization in many forms by other adults as well as peers (Whitbeck et al. 2001). This is most common for females and younger youth who may have more difficulty protecting themselves against physical attacks (Paradise and Cauce 2002, Whitbeck et al. 2001). Youth report that those who purport to be friends with another youth sometimes use the other person for sex, shelter, drugs, or money (Chun and Springer 2005).

Once these significant mental and physical health stressors are made clear, so too is the need for appropriate health care and support interventions for homeless youth. It is crucial that these youth have access to mental and physical health care before health issues become chronic and result in long-term quality of life decreases (Aviles and Helfrich 2004). Early intervention is crucial, as the longer a youth remains homeless, the greater the likelihood of him or her developing chronic physical and mental health issues (Brooks et al. 2004, Kidd 2003, Berdahl et al. 2005, Thompson et al. 2006a).

The need for such services is rarely met. Even where support exists, the number of barriers to accessing care means that existing services do not always reach their intended recipients. Access to care is particularly grave for rural homeless youth. It is a common belief that the homeless exist only in urban centres and not suburbia. The implications of this belief are a wide -spread lack of services for homeless individuals living outside of urban centres. Given the lack of resources to secure reliable transportation, rural homeless youth must often leave their current region in order to access services in more urban settings (Baker Collins 2013, Edwards et al. 2009). This can result in an influx of homeless individuals to urban centres that have facilities to aid the homeless.

To put this problem into context it is helpful to consult sources providing information regarding the geographic dispersal of homeless individuals. The American Interagency Council on the Homeless (1999) found, in a survey of 2938 homeless individuals, that $30 \%$ of these individuals did not live in urban centres (21\% in suburban/urban fringe areas and $9 \%$ in rural areas). As such, any approach to improving service access for homeless youth should take into account the unique needs of rural homeless youth.

The struggle to provide homeless youth with adequate support to meet their myriad physical and mental health needs clearly has a geographic (or, locational) component. As such, it is critical that in order to be comprehensive, proposed solutions take, at least in part, a geographic perspective.

\section{An Overview of Geographic Approaches to Improving Homeless Youth Services}

A brief history of the relationship between geographic and social service theory serves to set the stage for how geographic theory can be further harnessed, specifically in order to address the needs of homeless youth, particularly those living in rural environs.

In fact, geographic theory has long been applied to social services. Teitz's (1968) 'public facility location' theory acts as a landmark for the beginnings of geography applying itself to human and social concerns. The underlying premise of Teitz's early research was that optimal locations for public facilities differ from the optimal locations for private facilities. Though seemingly obvious at the present time, this theory had major implications, particularly by suggesting that urban geography can and should concern itself with social/political decisions. 
Before long, a considerable amount of research in geography that examined efficiency and equity in public service availability and access was published (DeVerteuil 2000).

However, it was not until the 1980s that urban geography was applied to social issues much in the same manner as it is today. The 1980s saw important research which implicated human behaviours in the 'production' of the urban environment. This movement incorporated elements of social psychology in taking into account client needs and behaviours along with the attitudes of communities (DeVerteuil 2000). Part of this movement included research attempting to delineate conditions leading to optimal service access for homeless individuals.

The late 1990s and early 2000s featured a number of influential works in which urban geographic theory was applied to issues of service access for homeless youth (e.g. Paraschiv 2012, Kurtz et al. 2005, Barry et al. 2002, DeVerteuil 2002). A great portion of studies examining service use and access among homeless youth provide both quantitative and qualitative data (a mixed methods approach). Such research provides an understanding of not only structural factors but also the narratives of the individuals who have experienced various barriers to care (Aviles and Helfrich 2004).

Much of this research has concerned itself with whether or not services should be 'clustered', as it is typical of service organization in large North American cities (DeVerteuil 2002). Often, the distance the youth must travel to arrive at a facility that provides a needed health care service precludes access, as the youth will often not have the resources, such as bus tickets, necessary to travel further than walking distance (Barry et al. 2002). Brooks et al. (2004) is an example of research aimed specifically at informing other researchers, policy makers, and youth service operators of the geographic issues affecting youths' ability to access care. Brooks et al. (2004) focus specifically on barriers to care as perceived by the youth themselves. Conducting their work in Los Angeles, California, they maintain that Los Angeles County does not fail to provide facilities offering appropriate health care for homeless youth. However, despite the quality of the region's services, they are under-utilized owing to their concentration in the core downtown area of Hollywood (located within Los Angeles County and characterized by high levels of drug use, drug dealing, and prostitution), limiting access for those living outside the urban core of Los Angeles County, namely rural homeless youth (Brooks et al. 2004).

Similarly, Barry et al. (2002), seemingly in favour of clustering homeless youth services to a degree, give the example of a youth who manages to access health care, but in doing so finds that she or he must access other services to fully meet her or his health care needs. For example, after painstakingly securing transport to an appointment with a physician, a youth may be required to get medication at a pharmacy, which may not be located near the physician's office. Again, this issue is of particular relevance to rural homeless youth. The solution proposed by Barry et al. (2002) is to have a multitude of services located in close proximity or at one site.

Arguing against the clustering of services are often those who suggest that the most effective means of providing health services to homeless youth is through outreach programs. Kurtz et al. (2005) have cited providing care via outreach interventions as a promising method of care delivery as it, in theory, eliminates the need for the client to have transport to the care facility. In the past, outreach efforts have been successful in providing street youth with hepatitis $B$ vaccinations, for example. 
Today, geographers have built a considerably large body of research literature on the mobility of homeless individuals. Even these analyses of mobility tend to examine solely mobility across and within urban centres. Specifically, it has been realized that there are significant geographic barriers to the homeless youth's ability to access health care (DeVerteuil 2002). Kidd (2003) points to the increased amount of literature focused on the service needs and barriers faced by homeless youth as a sign that homeless youth researchers are realizing the urgent need to fill gaps in research that informs interventions and barriers to access the services. That said, little research has directly - or in an applied manner - made specific recommendations for the location of services and how optimal location can reduce barriers to access, particularly for rural homeless youth.

\section{Call to Action}

The intersection of urban geography and research concerning homeless youth services has been implicit, rather than explicit. It has been theoretical, rather than applied. Researchers from both camps recognize the relevance of the other to their own field, with researchers specialized in youth homelessness highlighting the relevance of geography and the location of services (e.g. Baker Collins 2013) and geographers acknowledging their ability to comment on issues related to youth homelessness (e.g. Gibson 2011). However, direct partnerships between geographers and researchers specialized in youth homelessness have been rare. Greater partnership between these researchers holds promise for creating cost effective ways of identifying optimizations in service location that will better-serve homeless youth.

Understanding extant research in which access to health services for homeless youth has been viewed from a geographic perspective is helpful in identifying future areas of partnership. Despite some efforts to apply geographic theory to issues pertaining to social services and, more recently, a number of studies that explore geographic theory in relation to homeless youth, there remains little clarity for how best to plan for, and locate services. This lack of clarity is of particular disadvantage to homeless youth living in rural settings.

Ideally, youth homelessness researchers and clinicians will seek consultation from urban geographers in the planning of research and interventions that are influenced by the location of services. Given time and budgetary constraints, particularly in this often-under-funded area of work, researchers have limited opportunities to work together in such a capacity. This is particularly true given that there are few natural intersections such as mutually relevant professional events such as conferences. As such, it is necessary for both urban geography and youth homelessness researchers to proactively initiate collaboration.

In the absence of direct collaboration on research projects and the planning of interventions, the most effective manner of initiating collaboration may be, paradoxically, for urban geographers to independently produce analyses or publications related to issues of youth homelessness. By independently applying their unique skills in such a manner, urban geographers can demonstrate the full scope of their ability to positively influence the condition of homeless youth. These independent works will pave the way for further collaboration between geographers and professionals in fields such as psychology, social work, and nursing.

Of course, professionals from these fields have a responsibility to effectively engage geographers. This is particularly true given the positive influence that urban geography has had on the condition of adult homeless individuals. Leading and innovative professionals from areas outside of geography must recognize the value of a geographic perspective to issues of youth homelessness. As part of increasing awareness and spurning engagement, the author of this 
paper will seek to have it cross-published in publications related to fields more traditionally connected to homeless youth research and interventions.

This discussion has been meant to alert both homeless youth researchers and urban geographers, particularly in the face of the dire mental and physical health needs of homeless youth. For homeless youth researchers, there must be an awareness of the necessity of collaborating with urban geographers in order to better address the needs of these youth. For urban geographers, there exists an opportunity to extend the reach of their profession by collaborating with homeless youth researchers to make decision about the optimal location of facilities for this disadvantaged population.

Ultimately, research from the field of geography can inform decisions about homeless youth service location, improving the likelihood that members of this young, vulnerable population will receive the mental and physical health care that is critical to their long-term quality of life.

\section{References}

AVILES A., HELFRICH C. (2004), Life skill service needs: Perspectives of homeless youth, Journal of Youth and Adolescence 33, 331-338.

BAKER COLLINS S. (2013), Childhood stress and mobility among rural homeless youth, In Gaetz S., Karabanow J., O'Grady B. (Eds.), Youth Homelessness in Canada: A Reader, Canadian Homeless Research Network, Toronto, ON, 1-26.

BARRY P. J., ENSIGN J., LIPPEK S. H. (2002), Embracing street culture: Fitting health care into the lives of street youth, Journal of Transcultural Nursing 13, 145-152.

BERDAHL M. A., HOYT D. R., WHITBECK L. B. (2005), Predictors of first mental health service utilization among homeless and runaway adolescents, Journal of Adolescent Health 37, 145-154.

BROOKS R. A., MILBURN N. G., ROTHERHAM-BORUS M. J., WITKIN A. (2004), The system-of-care for homeless youth: Perceptions of service providers, Evaluation and Program Planning 27, 443-451.

CHUN J., SPRINGER D. W. (2005), Stress and coping strategies in runaway youths: An application of concept mapping, Brief Treatment and Crisis Intervention 5, 57-74.

DEVERTEUIL G. (2000), Reconsidering the legacy of urban public facility location theory in human geography, Progress in Human Geography 24, 47-69.

DEVERTEUIL G. (2002), Homeless mobility, institutional settings, and the new poverty Management, Environment and Planning 35, 361-373.

EDWARDS M. E., TORGERSON M., SATTEM J. (2009), Paradoxes of providing rural social services: The case of homeless youth, Rural Sociology 74, 330-355.

ELIAS B. M. (2009), Rural responses to uncovering the hidden aspects of homelessness in Ontario 2000 to 2007 (Unpublished doctoral dissertation), University of Toronto, Toronto.

ENSIGN J., BELL M. (2004), IIIness experiences of homeless youth, Qualitative Health Research 14, 1239-1254.

GIBSON K. E. (2011), Street Kids: Homeless Youth, Outreach, and Policing New York's Streets, NYU Press, New York and London.

HALCÓN L. L., LIFSON A. R. (2004), Prevalence and predictors of sexual risks among homeless youth, Journal of Youth and Adolescence 33, 71-80.

INTERAGENCY COUNCIL ON THE HOMELESS (1999), Homelessness: Programs and the people they serve, Government Printing Office, Washington, DC.

KIDD S. A. (2003), Street youth: Coping and interventions, Child and Adolescent Social Work Journal 20, 393-422. 
KURTZ S. P., SURRATT H. L., KILEY M. C., INCIARDI J. A. (2005), Barriers to health and social services for street-based sex workers, Journal of Health Care for the Poor and Underserved 16, 345-361.

NATIONAL ALLIANCE TO END HOMELESSNESS (2010), Geography of homelessness, Retrieved online from: http://www.endhomelessness.org/library/entry/geography-ofhomelessness.

PARASCHIV M. (2012), Urban (in) security and assessment of extreme poverty: Residents' perception referring to homelessness in Bucharest, Procedia Environmental Sciences 14, 226-236.

PARADISE M., CAUCE A. (2002), Home street home: The interpersonal dimensions of adolescent homelessness, Analyses of Social Issues and Public Policy 2, 223-238.

THOMPSON S. J., MCMANUS H., LANTRY J., WINDSOR L., FLYNN P. (2006a), Insights from the street: Perceptions of services and providers by homeless young adults, Evaluation and Program Planning 29, 34-43.

THOMPSON S. J., MCMANUS H., VOSS T. (2006b), Posttraumatic stress disorder and substance abuse among youth who are homeless: Treatment issues and implications, Brief Treatment and Crisis Intervention 6, 206-216.

TEITZ M. B. (1968), Toward a theory of urban public facility location, Papers in Regional Science 21, 35-51.

WHITBECK L. B., HOYT D. R., YODER K., CAUCE A. M., PARADISE M. (2001), Deviant behaviour and victimization among homeless and runaway adolescents, Journal of Interpersonal Violence 16, 1175-1204.

Initial submission: 04.01.2013

Revised submission: 25.05 .2014

Final acceptance: 10.06 .2014

Correspondence: University of Ottawa, Clinical Psychology Program, 136 Jean Jacques Lussier, Vanier Hall, Ottawa, Ontario K1N6N5

E-mail: jperr101@uottawa.ca 
